\title{
Mitos Bunuh Diri Di Gunungkidul Daerah Istimewa Yogyakarta (DIY)
}

\section{Suicide Myth In Gunungkidul Special Region Of Yogyakarta (DIY)}

\author{
Faika Rachmawati ${ }^{1}$, Tri Suratmi ${ }^{2}$ \\ Puslitbang Upaya Kesehatan Masyarakat Badan Litbangkes Kemenkes ${ }^{1}$ \\ Universitas Respati Indonesia ${ }^{2}$ \\ Email : faika_tvi@yahoo.co.id,tri2209@yahoo.co.id
}

\begin{abstract}
ABSTRAK
Bunuh diri adalah upaya seseorang yang lebih memilih kematian dari pada kehidupan dengan cara membunuh diri sendiri dengan sengaja. Gunungkidul merupakan daerah dengan kasus bunuh diri keempat tertinggi di Indonesia. Jumlah kasus bunuh diri pada tahun 20152017 adalah 90 warga di berbagai wilayah, pada kelompok lanjut usia (lansia $>60$ tahun). Salah satu penyebab tindakan bunuh diri adalah mitos tentang Pulung Gantung yang diyakini oleh masyarakat setempat. Tujuan penulisan untuk menggali informasi mengenai fenomena bunuh diri di Gunungkidul dikaitkan dengan kebenaran mitos Pulung Gantung serta menganalisis penyebab terjadinya bunuh diri masyarakat Kabupaten Gunungkidul. Metode penelitian yang digunakan adalah penelitian kepustakaan (literature review) dengan obyek penelitian yang digali dari media online, jurnal, artikel di jurnal, dari media internet dan dilakukan analisis deskriptif. Hasil review menyebutkan bahwa pelaku tindakan bunuh diri terbanyak berjenis kelamin perempuan dengan rentang usia kelompok dewasa muda dan dewasa lanjut sebanyak $55 \%$. Penyebab tindakan bunuh diri adalah depresi (43\%), dipicu oleh sakit fisik menahun (26\%), gangguan jiwa (6\%), kesulitan ekonomi (5\%), masalah keluarga (4\%), dan tanpa keterangan (16\%). Tetapi semuanya berujung pada satu masalah yaitu kemiskinan. Saran untuk mengurangi kasus bunuh diri antara lain; dengan memberikan sosialisasi kepada masyarakat terkait pencegahan bunuh diri, dengan cara yang lebih komunikatif dengan warga. Dengan melibatkan tokoh agama dan kegiatan keagamaan, membentuk tim reaksi cepat penanganan bunuh diri, respon cepat berasal dari informasi masyarakat sekitar sehingga dapat ditangani secara serius dan sedini mungkin. Partisipasi seluruh warga diperlukan untuk mengenali orang yang memiliki risiko bunuh diri, mendampingi dan menginformasikan ke pusat pelayanan kesehatan terdekat. Orang beresiko tinggi memiliki keinginan untuk melakukan bunuh diri adalah orang dengan sakit menahun, lanjut usia yang hidup sendiri, dan orang yang memiliki masalah ekonomi. Solusi promosi kesehatan yang tepat dapat mencegah masyarakat supaya masalah kejiwaan masyarakat Gunungkidul segera tertangani.
\end{abstract}

Kata kunci : Bunuh diri, Gunungkidul, Pulung Gantung

\begin{abstract}
Suicide is the effort of someone who prefers death to life by deliberately killing oneself. Gunungkidul is the fourth highest suicide area in Indonesia. The number of suicides in 2015-2017 was 90 residents in various areas of the elderly age group (elderly> 60 years old). One reason for this is the myth about the Pulung Gantung that is believed by the surrounding community. The purpose of writing to explore information about the phenomenon of suicide in Gunungkidul is associated with the truth of the myth of Pulung Gantung and analyzing the causes of suicide in Gunungkidul Regency. The research method used was literature review with research objects extracted from online media, journals, articles, and the internet and carried out descriptive analysis. The results of the review stated that the most female
\end{abstract}

http://ejournal.urindo.ac.id/index.php/kesehatan

Article History :

Sumbitted 03 April 2020, Accepted 29 Juni 2020, Published Juni 2020 


\section{Jurnal Bidang Ilmu Kesehatan}

perpetrators of suicide were 55 percent of the age range of young adults and advanced adults. The cause of suicide is depression (43\%), triggered by chronic physical (26\%), mental disorders $(6 \%)$, economic difficulties (5\%), family problems (4\%), and without information (16\%). But it all leads to one problem, namely poverty. Suggestions for reducing suicides include; by giving outreach to the community related to suicide prevention, in a more communicative way with citizens. By involving religious leaders and religious activities, forming a rapid reaction team to deal with suicide, the rapid response comes from information from the surrounding community so that it can be handled seriously and as early as possible. Participation of all citizens is needed to identify people at risk of suicide, accompanying and informing the nearest health service center. High-risk people who have the urge to commit suicide are people with chronic illness, elderly people who live alone, and people who have economic problems. Appropriate health promotion solutions can prevent the community so that the psychological problems of the people of Gunungkidul are immediately addressed.

Keywords : Suicide, Gunungkidul, Pulung Gantung

\section{PENDAHULUAN}

Bunuh diri menjadi pilihan orangorang yang putus asa dalam menghadapi kesulitan hidup. Hal ini sebagai pembenaran diri untuk menyelesaikan masalah tahap akhir atau istilah lainnya pelarian diri dari masalah. Bunuh diri adalah satu jalan untuk mengatasi macammacam kesulitan pribadi, berupa rasa kesepian, dendam, takut, kesakitan fisik, dosa, dan lain-lain. ${ }^{1}$ Organisasi Kesehatan Dunia, World Health Organization (WHO) menyebutkan bahwa bunuh diri telah menjadi masalah besar bagi kesehatan masyarakat di negara maju dan menjadi masalah yang terus meningkat jumlahnya di negara berpenghasilan rendah dan sedang. Hampir satu juta orang meninggal setiap tahunnya akibat bunuh diri. ${ }^{2}$ Ini berarti kurang lebih setiap 40 detik jatuh korban bunuh diri. $^{3}$ Negara Indonesia memiliki prevalensi angka yang cukup tinggi mengenai masalah bunuh diri dan ini menjadi masalah yang universal. Menurut data yang ada pada tahun 2016, Indonesia berada di peringkat 159 dalam hal tingkat bunuh diri di dunia. WHO mencatat bahwa kasus bunuh diri di Indonesia telah mencapai 3,7 per 100.000 penduduk. ${ }^{4}$ Data Riset Kesehatan Dasar (Riskesdas) 2013 menunjukkan, prevalensi gangguan jiwa berat pada penduduk Indonesia 1,7 per mil. Gangguan jiwa berat terbanyak di DI Yogyakarta, Aceh, Sulawesi Selatan, Bali, dan Jawa Tengah.Daerah Istimewa Yogjakarta dan Daerah Istimewa Aceh memiliki prevalensi gangguan jiwa berat 2,7 per mil. Kulonprogo menempati kasus teratas dengan prevalensi 4.67, disusul Bantul 4,0, dan Kota Yogyakarta 2,14. Gunungkidul berada di posisi keempat, meskipun demikian disinyalir bahwa terdapat cukup banyak kasus gangguan jiwa tak terungkap. Melalui data yang dihimpun oleh Dinas Kesehatan DIY pada tahun 2016, dengan total penduduk DIY 


\section{Jurnal Bidang Ilmu Kesehatan}

sekitar 3,594 juta, terdapat 12.322 di antaranya, yang merupakan Orang Dengan Gangguan Jiwa (ODGJ). Bantul menjadi daerah dengan jumlah ODGJ terbesar, mencapai 3.875 jiwa. Berturut-turut, daerah dengan jumlah ODGJ terbesar berikutnya, yakni Gunungkidul (2.730), Kulonprogo (1.995), Kota Yogyakarta (1.954) dan Sleman (1.768). ${ }^{5}$ Data yang terdokumentasikan di Kepolisian Resort (Polres) Gunungkidul mencatat bahwa sepanjang 2001-2017, telah terjadi 493 kasus bunuh diri di 19 kecamatan di Gunungkidul. Lebih dari $80 \%$ pelaku memilih dengan cara gantung diri untuk mengakhiri hidup mereka. Bahkan sejak Januari hingga Juni 2018, tercatat 19 penduduk telah meregang nyawa dalam belitan tali. Polres Gunungkidul mencatat, sepanjang 2018 lalu terdapat 30 kasus bunuh diri. Dan pada 2019 ini, sudah ada empat kasus bunuh diri yang terjadi. ${ }^{6}$

Bunuh diri adalah tindakan yang dapat menyebabkan kematian, disengaja, dilakukan oleh dirinya sendiri dan pelaku menganggap tindakannya sebagai jalan yang terbaik untuk menyelesaikan masalahnya. Orang yang meninggal akibat dibunuh orang lain meskipun yang dibunuh menginginkan kematian, tidak bisa dikategorikan bunuh diri. ${ }^{7}$ Budaya juga mempengaruhi perilaku bunuh diri, misalnya di Cina, dilaporkan perempuan lebih banyak melakukan tindakan bunuh diri, karena kultur disana memandang dalam perkawinan laki-laki dianggap mempunyai peran dan derajat yang lebih tinggi. Karenanya, ketika terjadi permasalahan lebih sering menyalahkan perempuan. Sehingga perempuan lebih mudah depresi dan putus asa dan memilih bunuh diri sebagai penyelesaian masalahnya (Jin \& Zhang, 1998). ${ }^{8}$ Sedangkan di Indonesia, kasus bunuh diri di Gunungkidul diyakini masyarakat setempat salah satu penyebabnya adalah mitos mengenai Pulung Gantung. Sehingga setiap kejadian bunuh diri selalu dikaitkan dengan mitos tersebut. Pulung Gantung merupakan jenis benda angkasa mirip balon berekor panjang warna biru yang berjalan di angkasa dari satu titik ke titik yang lain dan kemudian jatuh di suatu tempat. Kabarnya, apabila benda ini terlihat melayang di atas sebuah rumah warga, maka salah seorang penghuninya dalam waktu dekat akan melaksanakan ritual bunuh diri. Pulung Gantung secara simbolis bermakna keterpanggilan atau isyarat agar menggantung pada tali pengikat ternak. Bagi mereka yang memilih untuk melakukan bunuh diri merupakan takdir. Tahun 1992 Bupati Gunungkidul mengeluarkan surat perintah yang berisi serangkaian upaya untuk mencegah tindak bunuh diri yaitu dengan melakukan upacara tradisinal ruwatan. Namun upaya tersebut belum mampu menekan angka bunuh diri yang tinggi. ${ }^{9}$ 
Berdasarkan latar belakang tersebut maka perlu dilakukan penelusuran kepustakaan terkait fenomena kasus bunuh diri di Gunungkidul dikaitkan dengan mitos Pulung Gantung, serta membuat saran promosi kesehatan kepada pemerintah daerah sebagai upaya menekan tingginya kasus bunuh diri di kabupaten Gunungkidul.

\section{TUJUAN}

Tujuan penulisan untuk menggali informasi tentang fenomena bunuh diri di Gunungkidul dikaitkan dengan kebenaran mitos Pulung Gantung serta menganalisis penyebab terjadinya bunuh diri masyarakat Kabupaten Gunungkidul.

\section{METODE}

Metode penelitian yang digunakan adalah penelitian kepustakaan (literature review) dengan obyek penelitian yang digali dari media online, jurnal, artikel, dari mediainternet dan dilakukan analisis deskriptif.

\section{HASIL DAN PEMBAHASAN}

$\begin{array}{ll}\text { Kasus } & \text { bunuh diri dan Pulung } \\ \text { Gantung di } & \text { Kabupaten Gunungkidul, } \\ \text { Yogyakarta } & \text { merupakan fenomena }\end{array}$
tersendiri di Indonesia. Setiap tahun, ratarata 30 warganya mengakhiri hidup dengan cara ini. Sejak 2015 sampai November 2017 ini, sudah 90 warga bunuh diri, 88 orang dengan cara menggantung dan dua orang menceburkan diri ke sumur. ${ }^{10,11}$ Bunuh diri merupakan masalah yang kompleks, karena tidak disebabkan oleh alasan tunggal. Tindakan tersebut akibat interaksi yang kompleks dari faktor biologik, genetik, psikologik, sosial budaya dan lingkungan. Sulit menjelaskan mengenai penyebab orang memutuskan bunuh diri, sedangkan dalam kondisi yang sama bahkan lebih buruk, ada orang yang justru tidak melakukan bunuh diri. Berdasarkan beberapa penelitian yang telah dijabarkan di atas, peneliti menyimpulkan penyebab orang melakukan bunuh diridapat dikelompokkan kedalam tiga hal. Pertama, masalah individu seperti, depresi, hopelessness, frustrasi, malu, penyalahgunaan obat terlarang. Kedua, faktor lingkungan, misalnya keluarga, sekolah, teman, tempat kerja. Ketiga, faktor budaya dan kehidupan sosial lainnya. ${ }^{12}$

Dalam periode 2001-2008, wilayah kecamatan di Gunungkidul didominasi oleh kejadian bunuh diri. Kejadian per wilayah kecamatan dalam periode waktu tersebut berada dalam rentang 5-26 kejadian. Pada periode 2015-2017 ini, jumlah kejadian per wilayah kecamatan berada dalam rentang 2-12 kejadian. Pada periode 2001-2008, ada 10 wilayah kecamatan dengan kejadian dominan peristiwa bunuh diri berturutturut adalah Karangmojo, Semanu, Semin, Tepus, Wonosari, Nglipar, Playen, Ngawen, Patuk, dan Ponjong. Semua area tersebut adalah berada dalam sabuk utama 


\section{Jurnal Bidang Ilmu Kesehatan}

perkembangan sosio-ekonomi wilayah Gunungkidul (jalur transportasi utama Gunungkidul). Dari hasil penelitian bahwa usia yang melakukan tindakan bunuh diri didominasi oleh kelompok usia warga lanjut usia (lansia >60 tahun) atau 44\%, kemudian dewasa lanjut yakni 46 - 60 tahun sebanyak 31\% dan usia dewasa muda $18-45$ tahun sebanyak $24 \%$ dan sisanya $1 \%$ untuk usi $>18$ tahun pada periode 2015-2017. Pada periode tersebut kelompok usia dewasa muda dan dewasa lanjut atau yang biasa disebut usia produktif bekerja menunjukkan prevalensi kelompok tertinggi pelaku bunuh diri yaitu sebanyak 55\%. Profesi atau pekerjaan berdasarkan data kejadia tahun 2005-2008, pelaku bunuh diri di Kabupaten Gunungkidul didominasi oleh warga yang bekerja sebagai petani yakni sebesar $79 \%$, lalu oleh kelompok yang berprofesi sebagai pegawa swasta, buruh, wiraswasta) $11 \%$, pelajar $5 \%$, lain-lain $3 \% n$ dan PNS/TNI/Polri/Pensiunan 2\%. ${ }^{10,11}$

Kepercayaan tentang mitos Pulung Gantung yang terkait kasus gantung diri di Gunungkidul begitu melekat di masyarakat tetapi tak ada yang bisa menjelaskan kebenarannya. Pulung Gantung, makhluk gaib yang dipercaya bisa membuat manusia bunuh diri. Diyakini, bahwa Pulung Gantung ini adalah wujud baru dari sebuah arwah para leluhur yang keberadaannya ditolak oleh akhirat. Mitos yang berembus sangat kencang di masyarakat mengenai sebuah legenda mistis bernama Pulung Gantung. Dinamakan gantung karena rata-rata mereka yang tewas mengakhiri hidupnya dengan cara menggantung diri. Dalam setiap kasus bunuh diri yang terjadi, masyarakat selalu mengaitkannya dengan mitos yang satu ini. Pulung Gantung digambarkan seperti sebuah benda misterius berbentuk bola api yang berpijar berwarna merah kekuningan dan memiliki ekor atau buntut. Konon kabarnya, apabila benda ini terlihat melayang di atas sebuah rumah warga, maka salah seorang penghuninya dalam waktu dekat akan melaksanakan ritual bunuh diri. Menurut sumber dari warga sekitar ia tampak seperti sebuah benda namun juga terlihat hidup berkat kobaran apinya yang berkilatkilat serta sesekali meredup padam dan membara ganas namun tidak dapat dipastikan bahwa Pulung Gantung merupakan sebuah benda atau sesosok makhluk. Satu hal yang pasti, penampakan Pulung Gantung ini menjadi isyarat kuat akan adanya warga setempat yang bakal melakukan bunuh diri.

Menurut salah seorang sesepuh yang tinggal di dekat komplek pemakaman raja-raja Mataram, dahulu kala ketika terjadi perseteruan antara Majapahit dan Demak, para prajurit dan rakyat yang setia terhadap raja Brawijaya $\mathrm{V}$ melarikan diri ke arah Gunungkidul karena menganggap lokasi ini terpencil dan sulit dijangkau. Sang 


\section{Jurnal Bidang Ilmu Kesehatan}

raja yang memiliki kekuatan maha sakti, memutuskan untuk bersemedi dan melakukan muksa alias menghilang bersama raganya untuk menghadap yang maha kuasa. Tragis, para pengikutnya gagal mengikuti sang raja karena ilmunya masih cetek. Mereka yang gagal kemudian berubah wujud menjadi jenglot, atau makhluk kerdil yang hobi meminum darah manusia. Sedangkan, sebagian pengikut lain yang sama sekali tak memiliki kemampuan, jadi frustrasi dan menyerah menjalani hidup karena ditinggal pemimpinnya. Maka, karena dianggap sebagai jalan terbaik, mereka pun melakukan bunuh diri massal dengan cara menggantung diri. Peristiwa memilukan tersebut meninggalkan energi negatif yang hingga kini masih membekas di daerah Gunungkidul. Roh atau arwah yang ditolak oleh kehidupan selanjutnya tersebut, berganti wujud menjadi sebuah benda atau sesosok makhluk berbentuk bola api yang saat ini kita kenal sebagai Pulung Gantung dan tak henti-hentinya mengajak jiwa-jiwa yang kurang beruntung untuk mengakhiri hidupnya seperti mereka. Mitos yang berkembang di daerah Gunungkidul bahwa jika Pulung Gantung melewati daerah tersebut akan ada orang yang bernasib sial, mengakhiri hidupnya dengan cara gantung diri walaupun mitos belum bisa ditangkap secara nalar dan tidak bisa dijelaskan secara ilmiah tapi masih dianut oleh masyarakat Kabupaten Gunungkidul.
Pendapat warga masyarakat Gunungkidul mengenai semaraknya tindakan bunuh diri di daerahnya didukung oleh fakta penelitian Kurniati menjelaskan bahwa orang Gunungkidul memiliki persepsi atau pemahaman, yaitu siapa saja yang kejatuhan (ketiban) Pulung Gantung dipercayai menjadi faktor pendorong bagi orang tersebut bunuh diri. Menurut pengetahuan masyarakat, lokasi jatuhnya Pulung Gantung itu bisa tepat di atas rumah pelaku bunuh diri tersebut, di atas rumah tetangga dekatnya, atau di pohon sekitar rumahnya. ${ }^{13}$

Berdasarkan wawancara dengan pihak terkait mereka tidak pernah tahu secara pasti sejak kapan kisah tentang Pulung Gantung itu muncul dan dalam waktu kapan ia muncul, meskipun bunuh diri di Gunungkidul selalu dikaitkan dengan mitos Pulung Gantung. Hal ini mungkin karena angka bunuh diri cukup tinggi juga modus bunuh diri hampir semua dengan cara menggantung sehingga bunuh diri dalam masyarakat dikaitkan dengan Pulung Gantung. Beberapa penelitian telah mencoba mengungkap fenomena tersebut. Salah satunya oleh Lembaga Swadaya Masyarakat (LSM) Imaji yang menyebutkan bahwa faktor penyebab bunuh diri di Gunungkidul cukup beragam. Dari hasil pemeriksaan polisi dan medis yang dihimpun, penyebab utamanya adalah depresi (43\%). Pemicunya antara lain sakit fisik menahun 26\%, gangguan jiwa $6 \%$, 


\section{Jurnal Bidang Ilmu Kesehatan}

kesulitan ekonomi 5\%, masalah keluarga $4 \%$, dan tanpa keterangan sebanyak $16 \%$. Studi antropologi yang dilakukan oleh Darmaningtyas menyimpulkan bahwa masalah ekonomi dan kemiskinan merupakan faktor primer di balik kasus bunuh diri di Gunungkidul. ${ }^{13}$ Studi mikro lapangan yang dilakukan Darmaningtyas menyimpulkan bahwa masalah keluarga, gangguan jiwa, hingga sakit fisik berpangkal pada kemiskinan. Bila ditelisik lebih jauh dari segi sosial ekonomi, tingginya prevalensi gangguan jiwa berat di DIY sebetulnya lebih merupakan fenomena kantong-kantong kemiskinan di daerah tandus dan kering seperti di Gunungkidul, bukan potret DIY secara umum. Seperti diketahui selama ini, kasus bunuh diri akibat kesulitan ekonomi juga banyak terjadi di wilayah Gunungkidul. dimana daerah Gunungkidul merupakan daerah pegunungan dan perbukitan yang masih memiliki daerah tandus dan masih banyak daerah yang masih kesulitan dalam memenuhi kebutuhan air. Dalam keadaan seperti itu penduduknya harus berjalan beberapa kilometer untuk mendapatkan air hal ini menyulitkan warga yang mayoritas bermata pencaharian sebagai petani karena akan mengalami masa paceklik. Kepercayaan tentang mitos Pulung Gantung yang terkait kasus gantung diri di Gunungkidul begitu melekat di masyarakat tetapi tak ada yang bisa menjelaskan kebenarannya. ${ }^{13}$
Penyebab paling umum dan paling sering ditemui sebagai alasan mengapa seseorang dapat melakukan tindakan seperti bunuh diri adalah depresi. Gangguan suasana perasaan (gangguan mood) merupakan sekelompok penyakit yang biasanya mengarah ke depresi atau elasi (suasana perasaan yang meningkat) pasien dengan mood yang meninggi menunjukkan sikap yang meluap-luap, gagasan yang meloncat-loncat, penurunan kebutuhan tidur, peninggian harga diri dan gagasan kebesaran. Pasien dengan mood yang terdepresi merasakan hilangnya energi dan minat, perasaan bersalah, kesulitan konsentrasi, hilangnya nafsu makan, pikiran tentang kematian dan bunuh diri. Penurunan mood yang dialami penderita depresi sangat bermakna, hingga menyebabkan ketidaknyamanan dan gangguan dalam beraktivitas. Secara sederhana, depresi adalah suatu pengalaman yang menyakitkan dan perasaan tidak ada harapan lagi. Pada saat ini, depresi menjadi gangguan kejiwaan yang sangat mempengaruhi kehidupan, baik hubungan dengan orang lain maupun dalam pekerjaan. ${ }^{13}$

WHO memprediksikan pada tahun 2020, depresi akan menjadi salah satu penyakit mental yang banyak dialami masyarakat dunia. Depresi adalah suatu perasaan sedih yang sangat mendalam yang terjadi setelah mengalami suatu peristiwa dramatis atau menyedihkan, 


\section{Jurnal Bidang Ilmu Kesehatan}

misalnya kehilangan seseorang yang disayangi. Seseorang bisa jatuh dalam kondisi depresi jika ia terus-menerus memikirkan kejadian pahit, menyakitkan, keterpurukan dan peristiwa sedih yang menimpanya dalam waktu lama melebihi waktu normal bagi kebanyakan orang. Depresi dapat terjadi pada setiap orang, golongan manapun, keadaan sosial ekonomi apapun, serta pada usia berapapun. Tetapi umumnya depresi mulai timbul pada usia 20 sampai 40 tahun-an. Depresi biasanya berlangsung selama 6-9 bulan, dan sekitar $15-20 \%$ penderita berlangsung sampai 2 tahun atau lebih. Episode depresi cenderung berulang sebanyak beberapa kali dalam kehidupan seseorang. Menurut National Institute of Mental Health (Siswanto, 2002), gangguan depresi dipahami sebagai suatu penyakit tubuh yang menyeluruh (whole-body), yang meliputi tubuh, suasana perasaan dan pikiran. Ini berpengaruh terhadap cara makan dan tidur, cara seseorang merasa mengenai dirinya sendiri dan cara orang berpikir mengenai sesuatu. Gangguan depresi tidak sama dengan suasana murung (blue mood). Ini juga tidak sama dengan kelemahan pribadi atau suatu kondisi yang dapat dikehendaki atau diharapkan berlaku. Orang dengan penyakit depresi tidak dapat begitu saja "memaksa diri mereka sendiri" dan menjadi lebih baik. Pada pengamatan universal, prevalensi gangguan depresif berat pada wanita dua kali lebih besar dari pada laki-laki. Lebih banyaknya wanita yang tercatat mengalami depresi bisa disebabkan oleh pola komunikasi wanita yang ingin memberitahukan masalahnya kepada orang lain dan harapan untuk mendapatkan bantuan atau dukungan sedangkan pada laki-laki cenderung untuk memikirkan masalahnya sendiri dan jarang menunjukkan emosinya. ${ }^{14}$ Berbagai penelitian mengungkapkan golongan usia muda yaitu remaja dan dewasa awal lebih mudah terkena depresi. Hal ini terjadi karena pada usia tersebut terdapat tahaptahap serta tugas perkembangan yang penting yaitu peralihan dari masa anakanak ke masa remaja, remaja ke dewasa, masa sekolah ke masa kuliah dan bekerja serta masa pubertas ke masa pernikahan. Survei telah melaporkan prevalensi yang tinggi dari depresi terjadi pada usia 18-44 tahun.

Beberapa data epidemiologis barubaru ini menyatakan insidensi gangguan depresif berat meningkat pada usia kurang dari 20 tahun. Penurunan kecenderungan depresi pada usia dewasa diduga karena berkurangnya respon emosi seseorang seiring bertambahnya usia, meningkatnya kontrol emosi dan kekebalan terhadap pengalaman dan peristiwa hidup yang dapat memicu stres. Faktor-faktor yang diduga berperan pada terjadinya gangguan depresi ini, yaitu peristiwa-peristiwa kehidupan yang berakibat stressor 


\section{Jurnal Bidang Ilmu Kesehatan}

(masalah keuangan, perkawinan, pekerjaan, dan lain lain), faktor kepribadian, genetik, dan biologik seperti ketidakseimbangan neurotransmitter, gangguan hormon imunologik. Selain faktor biologis penyebab depresi juga bisa disebabkan karena faktor eksternal. penurunan mood, yang kemudian diikuti dengan penurunan kemampuan berpikir, proses pikirnya melambat, tidak bisa berkonsentrasi, pesimis, semua situasi dipandang dari sudut negatif. Hal tersebut sesuai dengan penyebab depresi masyarakat Gunungkidul yang cukup signifikan antara lain; kehilangan status pekerjaan dan mata pencaharian, kehilangan sumber pendapatan secara mendadak karena migrasi, gagal panen, krisis moneter, kehilangan pekerjaan, bencana alam, mendengar berbagai suara gaib untuk bergabung menuju surga, mengikuti kegiatan sekte keagamaan tertentu. Ketidakmampuan individu mengelola stres akan mengarahkan perilaku individu pada perilaku destruktif, dimana puncak dari perilaku destruktif adalah bunuh diri. Bunuh diri merupakan gangguan mental yang akut. Jika tidak ditangani dengan maksimal, sangat memungkinkan warga yang mengalami gangguan mental kuat tersebut memilih mengakhiri hidup dengan bunuh diri. Mitos Pulung Gantung ini melegitimasi tindakan bunuh diri masyarakat Gunungkidul sehingga bunuh diri dapat ditempatkan sebagai fakta simbolik dari proses komunikasi. Penelitian yang dilakukan Soetji Andari tahun 2017 menyebutkan pelaku bunuh diri paling banyak akibat dari depresi dan penyakit menahun. Depresi akibat dari kehilangan pekerjaan, tidak mencukupi kebutuhan keluarga, perceraian, perselingkuhan hingga putus cinta. Pelaku bunuh diri pada lanjut usia akibat dari penyakit menahun dan kesepian karena ditinggal anggota keluarga. ${ }^{15}$ Nevid, Rathus dan Greene tahun 2005 menyatakan bahwa tingkat depresi tetap lebih tinggi diantara lanjut usia yang hidup jauh dengan keluarga atau sanak saudara tentunya dapat menimbulkan perasaan kesepian, karena tidak ada lagi orang yang selama ini hidup bersama dan berbagi. ${ }^{16}$ Hampir seluruh lokasi kejadian bunuh diri berada di rumah dalam kondisi sepi, bisa di kamar tidur, kamar mandi, dapur artinya rumah merupakan tempat yang paling banyak sebagai tempat bunuh diri. Pelaku bunuh diri sebenarnya ingin menjalin komunikasi dengan orang lain untuk memecahkan permasalahan hidup yang tengah dihadapi namun tidak mampu mengakses media untuk menyampaikan maksudnya tersebut. ${ }^{15}$ Selanjutnya, penceritaan Pulung Gantung dan pelaksanaan serangkaian ritual pasca kejadian bunuh diri menjustifikasi bahwa tindakan bunuh itu sebagai suatu proses kematian yang alami dan dianggap wajar. Hasil penelitian

http://ejournal.urindo.ac.id/index.php/kesehatan 


\section{Jurnal Bidang Ilmu Kesehatan}

berdasarkan disertasi Wayan Suwena tahun 2016 tentang tindakan bunuh diri di Gunungkidul merupakan tragedi kemanusiaan. Penyebabnya masih menjadi sebuah misteri, maraknya kasus bunuh diri sebagai akibat pelaku bunuh diri terkena atau kejatuhan Pulung Gantung. Adanya mitos Pulung Gantung ini melegitimasi tindakan bunuh diri masyarakat Gunungkidul. $^{17}$

Promosi kesehatan menjadi salah satu upaya untuk meningkatkan kesehatan masyarakat melalui peningkatan perilaku dan lingkungan yang kondusif untuk hidup sehat. $^{18}$ Tujuan promosi kesehatan supaya meningkatnya kemampuan dan kemauan masyarakat untuk memelihara dan meningkatkan derajat kesehatan. Strategi Promosi Kesehatan yang dikenalkan oleh WHO pada tahun 1984 seperti advokasi untuk memperoleh komitmen guna mendukung program-program kesehatan, seperti rumusan masalah di atas bahwa untuk melaksanakan kegiatan promosi kesehatan jiwa di Gunungkidul selain melakukan upaya supaya masyarakat tidak terlalu menanggap serius apabila melihat penampakan Pulung Gantung, perlu dukungan kepala daerah agar semua stakeholder yang ada di Gunungkidul berperan aktif dalam pencegahan terjadinya kasus bunuh diri. Salah satunya regulasi kepala daerah agar semua dinas, instansi maupun lembaga menyusun program dan kegiatan dalam upaya pencegahan terjadinya kasus bunuh diri. Kemudian yang kedua bina suasana merupakan kegiatan yang membina suasana yang kondusif sehingga diperoleh dukungan sosial terhadap programprogram kesehatan. Setelah ada regulasi sebagai pedoman pelaksanaan kegiatan promosi kesehatan jiwa kita libatkan stakeholder terkait, seperti dari Kepolisian dengan Babin Kamtibmas, Dinas Kesehatan Kab/Kota atau Puskesmas bekerja sama dengan berbagai profesi diantaranya psikiater, psikolog, dokter, perawat, kader, rumah sakit jiwa dengan promosi kesehatan rumah sakit di luar gedung, kementrian agama berperan dalam pembinaan akhlak, Dinas Koperasi Perdagangan dan Industri untuk menangani masalah ekonominya. Kemudian yang terakhir adalah empowerment merupakan kegiatan untuk menggerakan masyarakat guna menumbuhkan tingkat kepedulian terhadap keadaan yang sedang dihadapi di Gunungkidul. Di daerah tersebut sudah ada LSM yang bergerak di bidang sosial kemanusiaan. Kegiatan mereka didukung dengan penambahan SDM supaya warga terlayani dengan konseling kesehatan jiwa. Kemudian model promosi kesehatan seperti Model PRECEDE adalah model yang dikembangkan oleh Green dan Kreuter pada tahun 1980, merupakan model yang paling cocok diterapkan dalam perencanaan dan evaluasi promosi 


\section{Jurnal Bidang Ilmu Kesehatan}

kesehatan, dikenal dengan model PRECEDE (Predisposing, Enabling, Reinforcing Causes in Educational Diagnosis and Evaluation) Merupakan arahan dalam menganalisis atau diagnosis dan evaluasi perilaku untuk intervensi pendidikan (promosi) kesehatan yang merupakan fase diagnosis. Predisposisi kasus tersebut di atas bahwa sesuai hasil analisis sementara oleh LSM setempat $43 \%$ penyebab kematian di Gunungkidul adalah depresi, maka sasaran promosi kesehatan jiwa difokuskan pada masalah depresi. Sebagai enabling faktor kita berdampingan dengan petugas kepolisian, petugas Rumah Sakit Jiwa (psikiater), petugas dari Kementrian Agama , petugas dari Dinas Koperasi Perindustrian dan Perdagangan dan UKM (sentra usaha kecil untuk membuka lapangan kerja baru) dalam penanganan masalah ekonomi. Sedangkan Reinforcing kita gunakan surat edaran kepala daerah tentang semua steakholder harus melaksanakan program dan kegiatannya berfokus pada penanganan kesehatan jiwa.

Koordinator kegiatan promosi kesehatan jiwa ada di Dinas Kesehatan Kabupaten Gunungkidul, sebagai pendukung kegiatan yaitu Kepolisian Resort Gunungkidul, kementrian agama wilayah Kabupaten Gunungkidul, Dinas Koperasi Perindustrian dan Perdagangan dan UKM dan Rumah Sakit Jiwa. Membuat jadwal promosi kesehatan jiwa untuk 6 bulan pertama dan dievaluasi setiap bulan.
Selanjutnya model pemberdayaan masyarakat melalui pengembangan upaya kesehatan bersumber daya masyarakat. Kader dilatih untuk memahami perilaku pasien gangguan jiwa, mengetahui gejala yang nampak, metode penanganan, dan pemberian pertolongan pertama pada pasien gangguan jiwa. Layanan kesehatan jiwa di masyarakat pada dilakukan dengan cara kader melakukan pendekatan terhadap keluarga dan orang dengan gangguan jiwa secara empatik. Kader berkomunikasi dengan sikap ramah dan terbuka. Faktor pendukung kemudahan penerimaan keluarga adalah karena kader berasal dari masyarakat setempat. Kader mengetahui dan memahami berbagai karakter keluarga dan orang dengan gangguan jiwa. Kader membangun komunikasi dan interaksi yang produktif dengan sikap yang empatik. Setelah sikap keluarga terbuka, kader menyampaikan informasi yang dibutuhkan. Kader memberikan edukasi kesehatan jiwa dan informasi layanan kesehatan jiwa. Kader merujuk penderita ke puskesmas, mengontrol pengobatan, dan mengupayakan berbagai akses dukungan sosial lain. Kader dilatih agar bisa membantu para psikiater, dokter dan psikolog yang amat terbatas sehingga penanganan kesehatan gangguan jiwa ini bisa terintegrasi dengan masyarakat. 
SIMPULAN

Memberikan sosialisasi kepada masyarakat terkait pencegahan bunuh diri, dengan cara yang lebih komunikatif dengan warga. Salah satunya melalui tokoh agama yang terus melakukan sosialisasi kepada warga melalui kegiatan keagamaan. Membentuk tim reaksi cepat penanganan bunuh diri, respon cepat berasal dari informasi masyarakat sekitar sehingga dapat ditangani secara serius dan sedini mungkin. Partisipasi seluruh warga diperlukan untuk mengenali orang yang memiliki risiko bunuh diri, mendampingi dan menginformasikan ke pusat pelayanan kesehatan terdekat. Orang beresiko tinggi memiliki keinginan untuk melakukan bunuh diri adalah orang dengan sakit menahun, lanjut usia yang hidup sendiri, dan orang yang memiliki masalah ekonomi. Solusi promosi kesehatan yang bisa diterapkan dalam pencegahan dan penanganan masyarakat supaya masalah kejiwaan masyarakat Gunungkidul segera tertangani.

\section{DAFTAR PUSTAKA}

Husein, M.A. 2012. Kajian Bunuh Diri. Jakarta; Adamsains

Unknown. 2017. “Mengapa Kita Bicara Bunuh Diri?", https://imaji.or.id/mengapa-kitabicara-bunuh-diri/ Linggasari, Yohannie. 2015. WHO: Tiap 40 Detik, Satu Orang Mati Bunuh Diri https://www.cnnindonesia.com/nasi

onal/20150911134959-20-

78094/who-tiap-40-detik-satu-

orang-mati-bunuh-diri

Unknown. 2017. "Kasus Bunuh Diri, Indonesia Tempati Posisi 8 di Asia Tenggara", https://lifestyle.sindonews.com/read \1190568/166/kasus-bunuh-diriindonesia-tempati-posisi-8-di-asiatenggara-1490164957

Unknown. 2018. "Jumlah Penderita Gangguan Jiwa di DIY Tertinggi di Indonesia", https://jogja.tribunnews.com/2018/ 02/21/jumlah-penderita-gangguanjiwa-di-diy-tertinggi-di-indonesia

Syambudi, Irwan. 2019. "Penyebab Tingginya Bunuh Diri di Gunungkidul Tak

Hanya

Ekonomi", https://tirto.id/detG

Gamayanti, Witrin. 2014. Usaha Bunuh Diri Berdasarkan Teori Ekologi Bronfenbrenner. Psympathic, Jurnal Ilmiah Psikologi Vol. 1, No.2, Hal: 204-230

Jin, S., \&Zhang, J. (1998). Effects of Physical and Psychological WellBeing on Suicidal Ideation. Journal of Clinical Psychology, Vol 54, No.4, 401-413

Darmaningtyas. 2002. Pulung Gantung: Menyingkapp tragedi bunuh diri di Gunungkidul. Yogyakarta: Salwa Press. 


\section{Jurnal Bidang Ilmu Kesehatan}

Unknown. 2017. “Mitos Pulung Gantung dan Upaya Menangani Kasus Bunuh Diri Di Gunungkidul”, https://www.bbc.com/indonesia/ind onesia-41194325

Polres Gunungkidul. 2013. Angka dan Data Kejadian Bunuh Diri. Gunungkidul: Polres Gunungkidul

Gamayanti, Witrin. 2014. Usaha Bunuh Diri Berdasarkan Teori Ekologi Bronfenbrenner. Psympathic, Jurnal Ilmiah Psikologi; Vol. 1, No.2, Hal: $204-230$

Darmaningtyas. 2002. Bunuh Diri Menyingkap Tragedi Bunuh Diri di Gunungkidul. Salwa: Press: Yogyakarta

Siswanto. 2010. Pendidikan Kesehatan Anak Usia Dini. Yogyakarta: Pustaka
Soetji Andari, 2017. Fenomena Bunuh Diri Di Kabupaten Gunungkidul. Sosio Konsepsia Vol. 7, No. 01

Nevid, J.S., Rathus, S.A., dan Greene, B. 2005. Psikologi Abnormal. Erlangga. Jakarta

Wayan Susena, Laksono, Setadi, 2016. Bunuh Diri: Sesat Penandaan Pulung Gantung di Gunungkidul, Disertasi Antropologi UGM

Notoatmodjo, Soekidjo. 2003. Pendidikan Dan Perilaku Kesehatan. Rineka Cipta. Jakarta

Nurmala, Ira. et al. 2018. Promosi Kesehatan. Airlangga University Press. Surabaya 
Jurnal Bidang Ilmu Kesehatan 